\title{
THE INFLUENCE OF THE SMARTPHONE USER'S CHARACTERISTICS ON THE INTENTION TO USE OF M-HEALTH
}

\author{
Zuhal Hussein $^{\star 1}$, Amran Harun ${ }^{2}$, Siti Waringin Oon ${ }^{3}$ \\ ${ }^{1}$ Universiti Teknologi MARA, Faculty of Business Management, Kota Bharu Campus, Wisma KUB, \\ Kota Bharu, Kelantan, MALAYSIA zuhal@kelantan.uitm.edu.my \\ ${ }^{2}$ Faculty of Business, Economic and Accountancy, Universiti Malaysia Sabah, Kota Kinabalu, \\ Sabah, MALAYSIA, aharun@ums.edu.my \\ ${ }^{3}$ Centre for Research on Women and Gender (KANITA), Universiti Sains MALAYSIA, \\ waringin@usm.my \\ ${ }^{*}$ Corresponding author
}

\begin{abstract}
M-Health is a new technology which has evolved from the unprecedented spread of mobile technologies as well as advancements in their innovative application to address health priorities. Implementing mobile technology will promote healthcare services with regards to improvement in accessibility, effectiveness, and affordability. This technology is growing rapidly since it was introduced 20 years ago. There are over 7 billion mobile cellular subscribers worldwide and 1.48 million of these are Malaysian subscribers. The penetration of mobile phone networks in Malaysia has transformed the way health services and information are accessed, delivered, and managed. While this technology is still new, there is a scarcity of research material on the acceptance of M-Health in Malaysia. This study proposes and empirically tests the smartphone users' characteristics such as users' sex, age, level of education and health condition as important factors that affected the adoption of new M-Health systems. To fill in this gap, this study is to explore the relationship between the smartphone users' characteristics, with the intention of using M-Health. This study has recruited 80 smartphone users in Sarawak through random sampling using a survey method. Data were analysed using Statistical Package of Social Sciences (SPSS) Version 17, and various statistical techniques were used such as descriptive analysis, T-Test and One-way ANOVA. Findings indicate that there are no significant differences between sex, age, level of education and having health problems were there was an intention to use M-Health. In conclusion, the acceptance of M-Health is not dependent on the users' characteristics, hence it is important for health technologies and mobile companies to handle different aspects in the planning and development of healthcare applications for a market strategy.
\end{abstract}

Keywords: Acceptance, Mobile technologies, M-Health, Smartphone users 


\section{INTRODUCTION}

Mobile health technology or M-Health technology is growing rapidly since it was introduced 20 years ago. The use of mobile gadgets that are connected with wireless technologies to support the realization of health objectives provides a great potential for transforming the face of health care delivery across the globe. In achieving this objective, M-Health technology provides support with the integration of mobile technology's advantages in the healthcare system (WHO, 2011). Implementing mobile technology will promote healthcare services with regards to improvement in accessibility, effectiveness, and affordability (Farhaan, Norris, Tony \& Mirza, 2008). Now, the mobile health industry is being predicted to grow to nearly $\$ 12$ billion by 2018 (Gruessner, 2015). The International Telecommunication Union (2015), reported that there are over 7 billion mobile cellular subscribers worldwide and 1.48 million of these are Malaysian subscribers. The penetration of mobile phone networks in Malaysia has transformed the way health services and information are accessed, delivered, and managed. Using mobile phone has many advantages when deployed as a healthcare tool. First, basic hand phone models can become powerful pieces of equipment when using conventional text messaging and calls. Users' can deliver real-time, critical information quickly and easily, which means those in emergency situations or living in remote areas can save on unnecessary travel to health centers to consult with doctors and nurses. However, as mobile devices become increasingly sophisticated, they can be used to do more than simply transmit information and advice. With the introduction of smartphones and wireless network facility enabled, this powerful device can be used to provide medical assistance, for example to be used for monitoring vital signs and body functions or as video conferencing equipment, as well as facilitating remote consultations. The establishment of mobile application will continue to transform healthcare innovativeness in the coming years. It is estimated that some 33 percent of smartphone users are likely to use the wellness application by 2017 (ITU, 2015). By having a smartphone in their hands, individuals are expected to engage in activities that can improve their health, as well as prevent disease. Mobile applications which are freely downloaded promote fitness, with guidance on diet and nutrition as well as incentives to work out, relax, or take up certain sports. However, users' characteristic factors may influence the usage of these applications, including preferences, demographics, and the patient's context such as health status, health services and information resources that are available (Longo et al., 2001).

First, previous studies on demographic factors such as users' sex were important factors that affected the adoption of new information systems. Research by Wang et al. (2011) and Wang et al (2014) reported that female users preferred to use the smartphone healthcare applications more than male users did. According to Conboy et al (2005), men seem to have greater interest than women in general information technology systems, such as smartphones and computers, but women have greater interest in health than do men. According to Kennedy et al. (2003), men used the Internet to search for information and to pursue more isolated recreational activities, but women used it for communicating with their friends and family and maintaining their social networks. Thus sex would affect the adoption of healthcare applications (Hussein, Wahid \& Saad, 2009).

Another important factor is age, which is expected to affect users' adoption of mobile health systems. This is based on an argument by Bigné et al. (2007) who posited that younger users tend to spend more time on Internet shopping activities compared to older people. Several researchers also postulated that younger people are more active in using mobile telecommunications facilities (Brown et al, 2002; Myring, 2012). Normally people that tend to use information devices are in their 20s and 30s (Kim, 2010). Therefore, based on what was reported earlier, it is expected that age would be a significant factor in the adoption of smartphone healthcare applications.

Educational level is the third factor, which is also important and need to be explored. Wang et al (2014) suggested that respondents who had the intention of using healthcare applications had a higher level of education compared to those without the intention of using healthcare applications. This is in line with a report by Illiger et al (2014), who stated that level of education was an important factor which contributed to the competent use of medical mobile technologies. The study also concluded that to fully realize the potential of mobile technologies in a health care context, one should include both the elderly as well as those who are educationally disadvantaged in all considerations.

Finally, a study done by Loo (2009) suggested that people who are having health problems are more likely to use mobile health services and tend to use and accept the mobile health technology. Whilst users' who are healthy perceived mobile phones which contain health services applications, as more of a "hassle than assistance". Therefore, the value of the mobile health technology was perceived to be greater for the patient with chronic health conditions who may need intensive management or greater access to care. 
Based on the justification above, and with the burgeoning mobile health applications market, it is necessary to carry out a research that looks into these customer characteristics, in order to develop specific application products or services that fulfil the various needs of customers'. Therefore, this study aims to investigate users' characteristics such as sex, age, level of education and health problems with regards to their intention to use mobile health applications.

\section{METHODOLOGY}

A total of 80 respondents who are smartphone users were selected as the sample for the study. It is important to note that the respondents are the smartphone users' as this study aims to capture the users' characteristics while using mobile health application. The scope of this study covers Sarawak, which is located in the Eastern Peninsular of Malaysia due to equal access of mobile health application regardless of their geographical strata, cultural and technological exposure between rural and urban area. The respondents were recruited randomly using purposive sampling across the state. A survey method was used as a method of data collection, while questionnaires were distributed in this study; which to provide respondents with sets of questions on socio-demographic characteristics and intention to use section. The respondents were asked for consent before proceed to the survey in order to ensure that ethical consideration was taken into account while conducting the study. Lastly, data were analysed using Statistical Package of Social Sciences (SPSS) Version 17, and various statistical techniques were used such as descriptive analysis, T-Test and One-way ANOVA.

\section{RESULTS}

Table 1: Socio demographic background

\begin{tabular}{|l|l|l|l|}
\hline \multirow{2}{*}{$\begin{array}{l}\text { Demographic } \text { / Social } \\
\text { Variables }\end{array}$} & \multicolumn{1}{|c|}{ Categories } & \multicolumn{1}{|c|}{$\mathbf{N = 8 0}$} & \\
\hline Sex & Male & \\
& Female & 34 & 42.5 \\
& $18-20$ & 46 & 57.5 \\
\hline Age (Years) & $21-30$ & 27 & 18.8 \\
& $31-40$ & 21 & 33.8 \\
& $41-50$ & 14 & 26.3 \\
& $51-60$ & 3 & 17.5 \\
& Primary & 23 & 3.8 \\
\hline Level of education & Secondary & 24 & 28.7 \\
& Tertiary & 33 & 41.3 \\
\hline Health problems & Yes & 11 & 13.8 \\
& No & 58 & 72.5 \\
& Don't know & 11 & 13.8 \\
\hline
\end{tabular}

Table 1 presents the distribution of the respondents based on sex, age groups, level of education, and health status. The percentage of female respondents is slightly higher, which accounts for more than half of the total respondents surveyed (57.5\%). Majority of the respondents were in the age group of 21-30 years (33.8\%), followed by age group of $31-40$ years $(26.3 \%)$, age group of $18-20$ years $(18.8 \%)$, age group of $41-$ 50 years $(17.5 \%)$ and the least was the age group of $51-60$ years $(3.8 \%)$. Most of the respondents having tertiary education which accounts for almost half of the total respondents surveyed (41.3\%). The lowest percentage of respondents was with primary education (28.7\%). In terms of having health problems, most of the respondents $(72.5 \%)$ mentioned that they do not have health problems, and equally mentioned that they had health problems $(13.8 \%)$ and do not know about their health problems $(13.8 \%)$. It can be speculated that majority of the respondents did not have health problems because majority of them were below 40 years old. 
Table 2: T-Test analysis

\begin{tabular}{|l|l|l|l|l|l|l|l|}
\hline Attributes & \multicolumn{4}{l|}{ Sex } & \multicolumn{2}{l|}{ Male } & \multicolumn{2}{l|}{ Female } \\
\cline { 2 - 8 } & $\mathbf{t}$ & $\mathbf{d f}$ & Sig. & $\mathbf{M}$ & SD & $\mathbf{M}$ & SD \\
\hline Intention to use & 1.06 & 80 & .293 & 3.7 & 0.58 & 3.5 & 0.51 \\
\hline
\end{tabular}

An independent-sample t-test was conducted to compare the sex - male and females, with regards to their intention to use $M-H e a l t h$. There was no significant difference between the score for male $(M=3.7, S D=0.58)$ and female $(M=3.5, S D=0.51), t(80)=1.06, p=.293$. These results suggest that sex does not have an effect on the intention to use M-Health.

Table 3: ANOVA Analysis by Elements of Respondents' Characteristics

\begin{tabular}{|l|l|l|l|l|l|l|}
\hline \multirow{2}{*}{ Attributes } & \multicolumn{2}{|l|}{ Age } & \multicolumn{2}{l|}{$\begin{array}{l}\text { Level of } \\
\text { education }\end{array}$} & \multicolumn{2}{l|}{$\begin{array}{l}\text { Having health } \\
\text { problems }\end{array}$} \\
\cline { 2 - 8 } & F-Value & Sig. & F-Value & Sig. & F-Value & Sig. \\
\hline Intention to use & 1.263 & .292 & .484 & .618 & 1.515 & .227 \\
\hline
\end{tabular}

One-way ANOVA was undertaken to test the differences between age, level of education and having health problems with the intention to use M-Health, where the results of the analysis were demonstrated in Table 2. Results revealed that there were no significant differences found on the age ( $F$-value=1.263), level of education ( $F$-value $=.484)$ and those having health problems $(F=1.515)$ of the respondents with their intention to use M-Health. This means that there were no significant differences in the F-value for respondents with different age levels, levels of education and whether they are having problems, no problems or do not know of their health status with regards to the intention to use M-Health.

\section{DISCUSSION AND CONCLUSION}

The findings found that the sex, age, level of education and having health problems had no significant differences on the intention to use M-Health. These results were supported by previous studies on demographic factors by Becker et al, (2015) and Lee et al, (2010). In contrast, in a study on whether the sex of the individual affects their intention to use healthcare applications, Wang et al (2014) suggested that female users preferred to use the smartphone downloaded with healthcare applications more, compared to the male users. This proves that female users have greater interest in their health than their male counterparts (Conboy, 2005). In terms of age, this study found that the difference in age groups had no effect on the intention to use M-Health due to the fact that majority of the respondents were young, with a majority of users' less than 40 years old. This indicates that mobile users feel they do not really need to use or are aware of using this health application. As such, these are likely because they are not diagnosed with any health problem. This is in line with a statement made by Loo (2009), that the value of the technology was perceived to be greater for the patient with chronic health conditions compared to healthy ones.

The result of this study rejects what has been mentioned by Illiger et al (2014) that the level of education was an important factor that contributes to the competent use of mobile health technologies. It can be assumed that the knowledge of the mobile health application is still limited among smartphone users and their interests in using smartphone is still at the basic level such as for communication, entertainment and social media. Since majority of them were young, as mentioned by previous studies which showed that younger people were more actively using mobile telecommunications for online shopping and entertainment (Bigné et al., 2007). Furthermore, male users tend to use the Internet to search for information and to pursue more isolated recreational activities, when compared to female users who are likely to use the Internet for communicating with their friends, family and maintaining their social networks (Kennedy et al., 2003).

It is also important to note that regardless of whether the respondents were having health problems or not and even did not know about their health status, there was no significant difference in their intention to use M-Health. Therefore it can be postulated that the respondents who did not know about this application because it was relatively new, are less likely to be aware of the application and its benefits.

In conclusion, this study has limitation on the number of respondents which is relatively small. For future research, they are expected to recruit more respondents to cover the whole Malaysia. These study results are expected to be used as a baseline data for the development, planning and operation of the marketing 
strategy of healthcare applications. Therefore, developers and managers of healthcare applications should consider these characteristics of current and potential customers to improve the adoption of healthcare applications.

\section{ACKNOWLEDGMENT}

The author would like to acknowledge the research project funded by the Ministry of Higher Education (MOHE) under the Fundamental Research Grant Scheme (FRGS) and Universiti Teknologi MARA (UiTM), Project No: $600-R M I / R F G S 5 / 3 / 122$ for the publication of this paper.

\section{REFERENCE LIST}

Becker, S., Brandl, C., Meister, S., Nagel, E., Miron-Shatz, T., Mitchell, A \& Kribben, A. (2015). Demographic and Health Related Data of Users of a Mobile Application to Support Drug Adherence is Associated with Usage Duration and Intensity. http://dx.doi.org/10.1371/journal.pone.0116980

Bigné, E., Ruiz, C., \& Sanz, S. (2007). Key drivers of mobile commerce adoption an exploratory study of Spanish mobile users. Journal of Theoretical and Applied Electronic Commerce Research, 2(2), 4860.

Brown, I., Cajee, Z., Davies, D., \& Stroebel, S. (2003). Cell phone banking: Predictors of adoption in South Africa-an exploratory study. International Journal of Information Management, 23(5), 381-394

Conboy, L., Patel, S., Kaptchuk, T. J., Gottlieb, B., Eisenberg, D., \& Acevedo-Garcia, D. (2005). Sociodemographic determinants of the utilization of specific types of complementary and alternative medicine: an analysis based on a nationally representative survey sample. Journal of Alternative \& Complementary Medicine: Research on Paradigm, Practice, and Policy, 11(6), 977-994

Gruessner, V. (2015). The History of Mobile Health: From Cell Phones to Wearables. MHealth Intelligence, 21 July.

Farhaan, M. Norris, T. \& Stockdale, R. (2008). Mobile technologies and the holistic management of chronic diseases. Health Informatics Journal. DOI: 10.1177/1460458208096559

Illiger, K., Hupka, M., Jan, U.V., Wichelhaus, D. \& Albrecth,U.V.(2014). Mobile Technologies: Expectancy, Usage, and Acceptance of Clinical Staff and Patients at a University Medical Center. JMIR Mhealth Uhealth, 2(4): e42. doi: 10.2196/mhealth.3799

International Telecommunication Union (2015). ICT facts \& figures.

Kennedy, T., Wellman, B., \& Klement, K. (2003). Gendering the digital divide. IT \& Society, 1(5), 72-96

Lee, S. J., Kim, Y. W., Seoh, H. S., \& Lee, B. G. (2010). Acceptance and rejection of smartphones and application genre repertoire. In Korean society for internet information conference, Seoul, Korea

Longo, D.R., Patrick, T.B. \& Kruse, R.L. (2001). The natural history of the use of healthcare information by women with breast cancer: a conceptual model, AMIA Annual Symposium proceedings, pp. 413-417.

Loo, J.L.(2009). Acceptance of Health Services on Mobile Phones: A Study of Consumer Perceptions. PhD Dissertation. Chapel Hill

Myring, J. (2012). HighBeamResarch, http://www.highbeam.com, accessed Apr. 15, 2016. Available from: http://www.highbeam.com/doc/1G1-108911848.html.

Kim, S. H. (2010). Effects of perceived attributes on the purchase intention of smart-phone. Journal of Korea Contents Association, 10(9), 318-326.

Wang, B.R., Park, J.Y., Chung, K.Y \& Choi, I.Y.(2014). Influential Factors of Smart Health Users according to Usage Experience and Intention to Use. Wireless Pers Commun, 79:2671-2683. DOI 10.1007/s11277-014-1769-0

Wang, B. R., Park, J. Y., \& Choi, I. Y. (2011). Influencing factors for the adoption of smart phone healthcare application. Journal of Korea Contents Association, 11(10), 396-404

WHO (2011). mHealth: New horizons for health through mobile technologies. 